\title{
Thyroidectomy under Local Anaesthesia: A Viable Option in a Resource Limited Community
}

\author{
Enoch Auta Dahilo1 ${ }^{*}$, David Femi Folorunsho', Fredrick M. Damtong1, Olumide Akitoye ${ }^{1}$, \\ Ibeneche Onyemuchechi Gbujie1, Semen Stephen Yikawe², Emmanuel Sara Kolo³, \\ Titus Sunday Ibekwe ${ }^{1}$
}

\author{
${ }^{1}$ Department of ENT/Head \& Neck Surgery, University of Abuja Teaching Hospital, Abuja, Nigeria \\ ${ }^{2}$ Department of ENT/Head \& Neck Surgery, Nigerian Air Force Hospital, Abuja, Nigeria \\ ${ }^{3}$ Department of ENT/Head \& Neck Surgery, Aminu Kano Teaching Hospital, Kano, Nigeria \\ Email: ^edahiloa@yahoo.com, dhlit95@gmail.com
}

How to cite this paper: Dahilo, E.A., Folorunsho, D.F., Damtong, F.M., Akitoye, O., Gbujie, I.O., Yikawe, S.S., Kolo, E.S. and Ibekwe, T.S. (2021) Thyroidectomy under Local Anaesthesia: A Viable Option in a Resource Limited Community. International Journal of Otolaryngology and Head \& Neck Surgery, 10, 383-391.

https://doi.org/10.4236/ijohns.2021.105035

Received: June 26, 2021

Accepted: September 3, 2021

Published: September 6, 2021

Copyright $\odot 2021$ by author(s) and Scientific Research Publishing Inc. This work is licensed under the Creative Commons Attribution International License (CC BY 4.0).

http://creativecommons.org/licenses/by/4.0/

\begin{abstract}
Background: In most centers worldwide, thyroidectomy is performed under general anaesthesia as a result of advances in anaesthetic technique, consideration for patients' safety and surgeons' convenience. However, in some developing countries such as Nigeria, facilities and expertise for general anaesthesia are not equitably distributed. As such, they are not available in some health centers especially in the rural communities. Hence, the need to explore other suitable alternatives such as operating under local anaesthesia. Aim: This study aims to highlight the feasibility and safety of thyroidectomy under local anaesthesia at a surgical outreach in a rural community in Nigeria. Patients and Methods: The study site was conducted at Bethany Medical Centre, Gboko, Benue State, Nigeria. It was a one-week surgical outreach. Neck infiltration with local anaesthesia was carried out using $2 \%$ xylocaine with adrenaline 1:200,000 and a standard open technique was used to carry out all thyroidectomies. Results: Out of seventy (70) patients that presented during the study period, $31(44.3 \%)$ met the inclusion criteria and were operated within the seven (7) days period. There were $3(10.7 \%)$ males and 28 (89.3\%) females. There ages ranged between 22 to 65 years, average was 43 years. The average duration of surgery was 90 minutes, and 3 days' hospital stay. Those followed up two weeks post-operation recuperated well with no notable complications. Conclusion: Thyroidectomy under local anaesthesia is safe and feasible in our rural communities and in selected cases can be a suitable alternative to general anaesthesia.
\end{abstract}

\section{Keywords}

Thyroidectomy, Local Anaesthesia, Goiter, Nigeria 


\section{Introduction}

Thyroidectomy under local anaesthesia (LA) dates back in history. It was pioneered by Thomas Dunhill \& Theodor Kocher over 100 years ago [1] [2]. As anaesthesia methods were refined and general anaesthesia became safer, LA became restricted to patients with contraindications to general anaesthesia and to patients living in medically resource-sparse locations [1]. In most centers worldwide, thyroidectomy is currently performed under general anaesthesia as a result of improvements in technique and for overall patient safety [3] [4] [5] [6]. In addition, it ensures good airway and blood pressure control, excellent surgeon comfort and appropriate patient positioning throughout surgery [4] [5].

However, in some developing countries such as Nigeria, facilities and expertise for general anaesthesia are not equitably distributed. As such, they are not available in some health centers especially in the rural communities. Hence, the need to explore other suitable alternatives such as operating under LA. Among other advantages, it has been reported that recurrent laryngeal nerves are better preserved in thyroidectomy under LA and the cost is significantly cheaper [2] [7]. Moreover, the presence of some co-morbid disease conditions may preclude the choice of general anaesthesia in some patients. Some general surgeons and Otorhinolaryngologists have reported successes with LA, with or without sedation for thyroidectomies. This is in addition to the safety and efficacy of thyroidectomy under LA already highlighted [3] [8] [9]. Notwithstanding, there still exist a dearth in literature the experiences and outcomes of thyroidectomy under LA in our environment. This study aims to highlight the feasibility and safety of thyroidectomy under local anaesthesia in a rural community in Nigeria.

\section{Patients and Methods}

\subsection{Study Design}

This was a prospective study.

\subsection{Study Site}

The study was carried out at Bethany Medical Centre, Gboko Benue State, Nigeria over a one-week period of a surgical outreach (Figure 1).

\subsection{Patient Selection/Sampling}

Patients were recruited into the study from people residing along the "goiter belt" of North Central Nigeria and who were to have surgery at the Bethany Medical Centre, Gboko Benue State, Nigeria during the study period. Consecutive sampling method was used to recruit participants into this study. Patients were recruited as they presented for surgery. The total number of patients recruited was determined by the number of patients available for surgery who met the inclusion criteria and consented to take part in the study. Patients with clinical diagnosis of simple goiters that met the inclusion criteria were enrolled into the study. The following were contraindications (Exclusion criteria). 

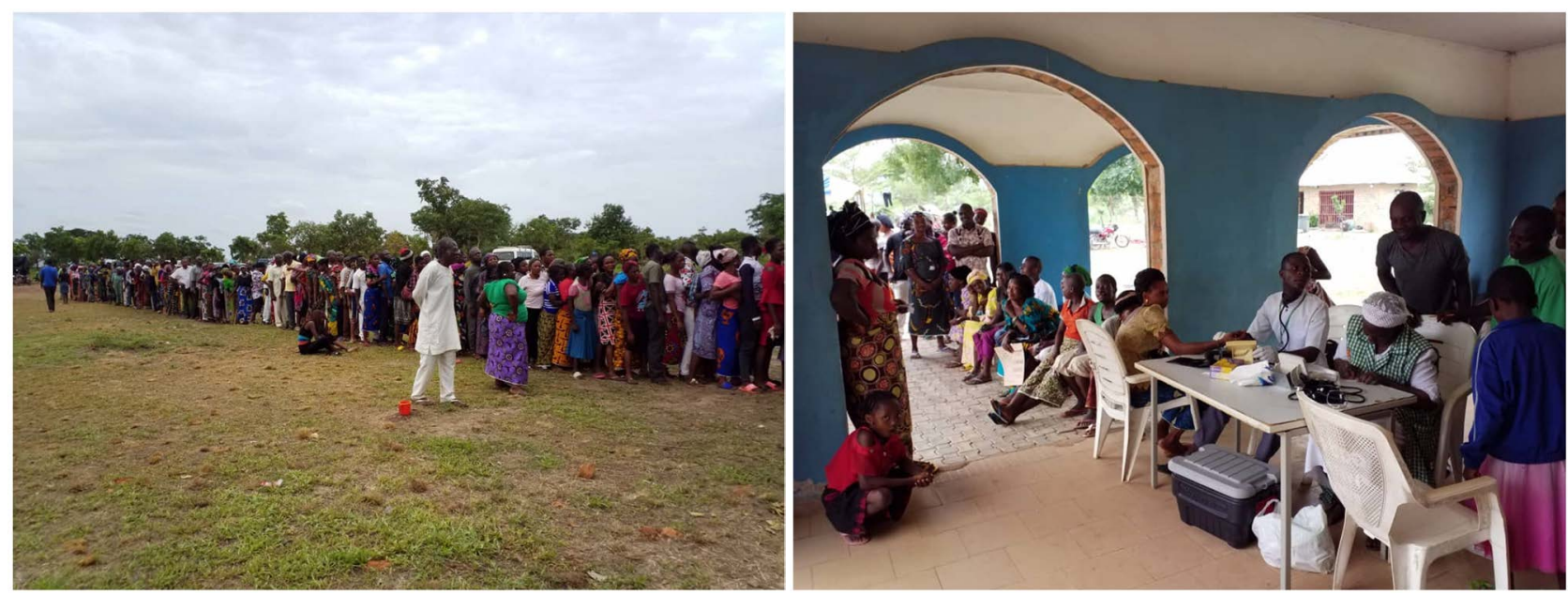

Figure 1. Rural hospital patients' selection arena.

- Patient unable to verbally communicate.

- Giant goiters.

- Previous thyroid surgeries.

- Sleep apnoea.

- Severe claustrophobia/anxiety.

- Morbid obesity.

- Retro-esophageal, retro-tracheal extension of goiter.

- Suspected thyroid cancer.

\subsection{Procedure}

Patients had their history taken, and thereafter their examinations done by the attending doctor. They had routine full blood count, blood sugar, urea \& electrolytes, urinalysis, retroviral screening and thyroid function test done. There were no facilities for histology and radiology at the Centre. Every patient had two pints of whole blood screened and cross-matched. Patients were first counseled on what to expect at surgery; the pain of neck infiltration, anticipated discomfort of prolonged neck extension and tissue manipulations. They were encouraged to communicate pains or other discomfort in the course of surgery by speaking and not neck movements. Routine cleaning and draping were applied exposing the nose and mouth to allow patient to breath and also have verbal interactions (Figure 2). The theatre had a standby anaesthetic machine in case any patient will require conversion to general anaesthesia and blood pressure was monitored regularly. The anaesthetic team reviewed all the patients and closely monitored their vital signs all through the surgical procedure. Intravenous infusion of dexterous saline, analgesics and antibiotics were given intra and post operatively.

Sub-platysmal neck infiltration was carried out with about $20 \mathrm{mls}$ of $2 \%$ xylocaine/adrenaline $(1: 200,000)$ using a $23 \mathrm{G}$ needle, starting with the incision line then into the inferior and superior flaps (i.e. from the suprasternal notch to 


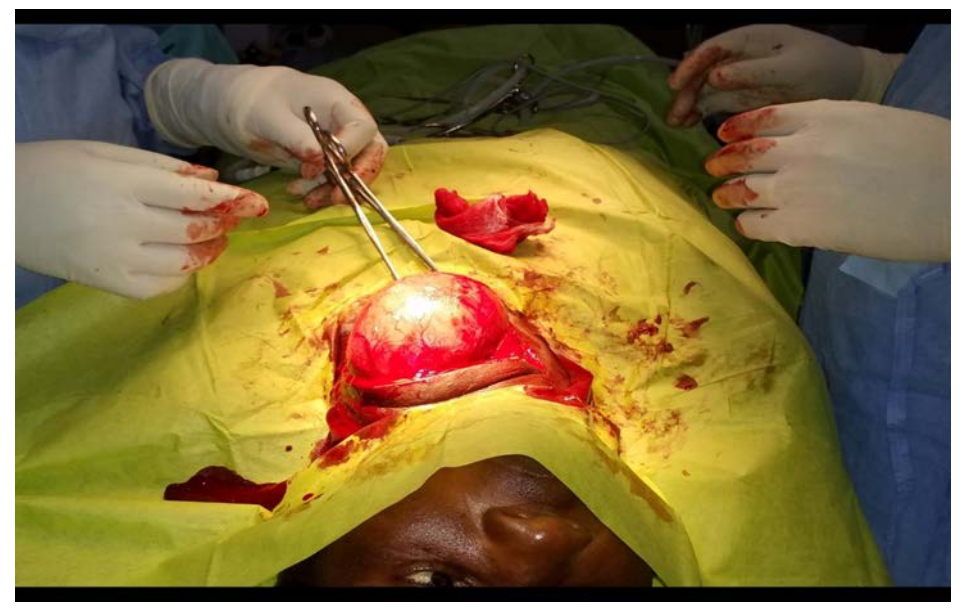

Figure 2. Demonstrating patient exposure during surgery.

above the thyroid cartilage, and laterally to anterior borders of sternocleidomastoid or lateral borders of the goiter). A time interval of 10 minutes was given between the time LA was applied and skin incision. A standard open technique was used to carry out all the thyroidectomies [10] [11] except for lateral extension of incisions in some patients to accommodate the shape, size and site of the goiter. Drains were inserted to prevent post op hematoma formation (Figure 3). They were nursed post operatively in cardiac position and spent at least three (3) days under medical surveillance before discharge. The variables investigated in this study were; Duration of surgery, Types of thyroidectomies conducted, Complications of surgery, Conversion rate from local to general anaesthesia, Duration of hospital stay, Patient satisfaction with the surgery and Indications for surgery. Above were recorded in their case notes.

\subsection{Limitations of the Study}

The limitations of this study were inability to evaluate all the variable in detail being an outreach setting, most parameters were estimated, we decided to report this outreach to lend our voice on the viability of thyroidectomy under local anaesthesia. Others were: inability to follow up the patients post op, lack of histopathology facilities for proper patient evaluation pre op (FNAC) and to characterized the excised tissues post op.

\section{Results}

Out of seventy (70) patients that presented during the study period, $31(44.3 \%)$ met the inclusion criteria and were operated. There were 3 (10.7\%) males and 28 (89.3\%) females. The male female ratio was approximately $1: 10$. Their ages were between 22 to 65 years, average age was 43 years. The commonest indication for surgery was cosmetic. An average of 5 patients were operated per day over 7 days' period. Five (16.1\%) had bilateral total thyroidectomy, 12 (38.7\%) had subtotal thyroidectomy while 14 (45.2\%) had single lobectomy (Table 1$)$. The duration of surgery ranged from 45 minutes to 135 minutes, with an average of 


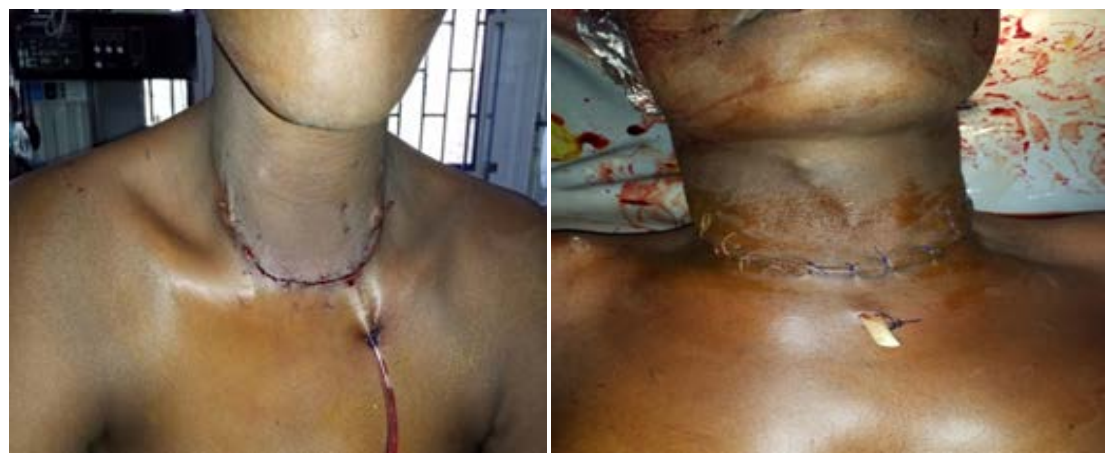

Figure 3. Demonstrating redivac and penrose drains used at the outreach.

Table 1. Types of thyroidectomies carried out.

\begin{tabular}{ccc}
\hline Type of Thyroidectomy & Frequency & Percentage (\%) \\
\hline Bilateral Thyroidectomy & 5 & 16.1 \\
Sub-total Thyroidectomy & 12 & 38.7 \\
Single Lobectomy & 14 & 45.2 \\
\hline
\end{tabular}

90 minutes. The average hospital stay was 3 days. No patient had the need to convert surgery from local to general anaesthesia. There were no significant intra and post-operative complications. Those followed up 2 weeks post op were recuperating well with no notable complications. All patients were satisfied with their surgeries post operatively.

\section{Discussion}

In this study, we had $3(10.7 \%)$ males and 28 (89.3\%) females, with a male: female ratio of 1:10. Goiters are generally more common in females [1] [2] [10] [11], so it is expected that thyroidectomies will be common among females as well. Similar findings have been reported by other authors. In a study carried out among patients who had thyroidectomy done under LA due to contraindication to GA, Kamran and colleagues reported 81 females and 19 males [12]. Ahmad and colleagues reported a female preponderance ( 22 females, and 8 males) in a cross sectional study of thyroid surgery under LA [13]. Similar findings of female preponderance among patients that had thyroidectomy under LA were also reported by other authors [14] [15] [16]. Eke et al. did not report any male patient among the 15 patients with giant goiters who had thyroidectomies under LA in their study [9]. However, the study by Eke and colleagues was a hospital based study with a small sample size. It will be difficult to extrapolate their findings as a representation of the general population.

The age range in this study was 22 to 65 years, with an average age of 43 years. This age range is similar to what was observed in other studies [9] [13] [14], however the mean age in some of these studies has been observed to be lower than what we observed in this study [12] [13] [14] [17]. Eke and colleagues however reported a mean age of 44.8 years, which is similar to the average age re- 
ported in this study [9]. This study and the one conducted by Eke and colleagues were all carried out in Benue State, Nigeria. This region of Nigeria falls within the goiter belt of the Nigeria. Goiters are common in this region, and many people live with their goiters and do not bother to seek medical attention, probably because it is common and the locals do not consider it a problem. For the few that may want to seek medical attention, the high cost of medical interventions and poor access to reliable medical facilities further discourage them. Many of them will either present late with complications or seek medical care to remove the goiters for cosmetic reasons in the setting of a free medical outreach as was the case in this study. It is therefore not surprising that cosmesis was the most common indication for thyroidectomy in this study. Another study conducted in the same environment also reported cosmesis as the most common indication for thyroidectomy among those who had their surgeries done under LA [9].

In this study, 14 (42.4\%) patients had single lobectomy, 12 (36.4\%) had subtotal thyroidectomy, while 5 (15.2\%) had bilateral thyroidectomy. Bilateral thyroidectomy and total thyroidectomy are generally the least common types of thyroidectomies done under LA by surgeons as compared with lobectomies [12] [13] [15] [16]. Aliyu and colleagues in a descriptive study of thyroidectomy under LA in a poor resource setting in Northeastern Nigeria reported subtotal thyroidectomy among $49.2 \%$ of their patients, near total thyroidectomy among $47.5 \%$ of their patients and total thyroidectomy among only $3.4 \%$ of their patients [16]. A cross sectional study on thyroid surgery under LA in Bangladesh among 30 patients reported hemi-thyroidectomy among 16 (53.3\%) patients, subtotal thyroidectomy among 8 (26.7\%) patients and total thyroidectomy among 6 (20\%) patients. Surgeons carefully select patients they offer thyroid surgeries under LA. In certain instances, they deliberately exclude patients with toxic and malignant goiters [9]. This is likely to account for the low numbers of patients having total thyroidectomy in this study.

The average duration of surgery in this study was 90 minutes (45 to $135 \mathrm{mi}$ nutes). This is similar to what was reported by other authors [9] [12] [13] [15] [17]. In a study conducted in Potiskum, Nigeria, the authors reported a mean duration of surgery of 40 minutes [16], much lower than what was observed in this study. But because most of these studies did not clearly define the period they consider as the duration of surgery, it is difficult to compare their findings. However, it is a well-established fact that thyroidectomies done under LA have the advantage of having shorter duration of surgery than those performed under GA [1] [2] [15]. In a study of General and Local Anaesthesia among 130 patients undergoing thyroidectomies in a University Hospital in Bulgaria, the authors observed that the average duration of surgery under LA was 98 minutes, while the average duration of surgery under GA was 127 minutes [15]. Banasiewiecz T et al. [18] reported an average operation time of 127 minutes, while Chintale SG et al. [11] reported a duration of 50.5 minutes and also observed about $40 \%$ reduction in cost of surgery, when compared with the use of general anaesthesia. Our average operation time of 90 mins, could probably be attributed to the fact 
that most (43.4\%) of our patients had lobectomy which was carried out under 60 mins. The time in between surgeries was shortened in our study. This was due to the fact that patients had LA, which was not associated with delays in between surgeries as a result of recovery from general anaesthesia. This was the reason why we could operate up to five patients per day. We also observed that removing the cost of general anaesthetic agents significantly reduced the cost of surgery.

Another selling point of the proponents of thyroidectomy under LA is the shorter hospital stay. The average hospital stay in this study was 3 days. Eke et al. and Ojuka et al. reported similar average hospital stays of 3 and 2 days respectively [9] [17]. However, in studies where the surgeries were carried out as day cases, the duration of hospital stay was in hours [14]. This was not the case in our study due to the peculiarity of the environment where the study was carried out. There was no significant post-operative complications and patients were satisfied with their surgeries post-operatively, in this study. We did not experience complications with our patients, probably due to the low volume of patients. Our patients communicated with us all through surgery. This helped to monitor for complications, counsel and reassure them. Kamran and colleagues reported bleeding in two patients post-operative [12]. They also observed extreme satisfaction among the participants following surgery [12]. Rifat L et al. [10] also reported same experience of satisfaction following surgery with their patients. Ahmed et al. reported hematoma and wound infection in one patient each [13]. Aliyu and colleagues reported hypercalcemic tetany in one patient, surgical site infection among 2 patients and keloid among 2 patients (Aliyu et al.). Spanknabel et al. [6] reported post-operative wound haematoma in $0.5 \%$. None of our patients had immediate post-operative haematoma as a complication. This also could be due to low patients' volume, selection and the use of redivac drain for all who had total and subtotal thyroidectomies (Figure 3). Drains were removed by the second day and patients discharged on the third day. The general condition at discharge was good. This agrees with the experience of Banasiewicz $\mathrm{T}$ et al. [5]. Chintale SG et al. [11] reported drain removal within 24 hours and discharge by second day. Tissue samples were sent to nearby tertiary hospitals for histology.

\section{Conclusion}

Thyroidectomy under local anaesthesia is quite safe and can be a suitable alternative to general anaesthesia at surgical outreach settings in resource challenged communities or when general anaesthesia is contraindicated. This approach, with careful selection and intra-operative monitoring, can be adopted in tertiary institutions to reduce cost of surgery for poor patients. We encourage surgeons to participate in surgical outreaches as part of their community service and for the purposes of skill acquisition and training.

\section{Conflicts of Interest}

The authors declare no conflicts of interest regarding the publication of this paper. 


\section{References}

[1] Santosh, U.P., Prashanth, K.B., Sharma, J.M., Nivedeeta, J.P., Srijoy, G., Sumanth, K.R. and Triveni, K.M. (2015) Thyroidectomy under Regional Anaesthesia: An ORL Perspective. Journal of Clinical and Diagnostic Research, 9, MCO1-MCO4.

[2] Milan, S.A., Wu, L.S. and Sosa, J.A. (2014) Thyroidectomy under Local Anesthesia. Current Surgery Reports, 2, Article No. 37.

https://doi.org/10.1007/s40137-013-0037-7

[3] Dunhill, T.P. (1907) Exophthalmic Goiter: Partial Thyroidectomy under LA. Intercolonial Medical Journal of Australasi, 49, 195-200.

[4] Santosh, U.P., Prashanth, K.B., Sharma, J.M., Nivedeeta, J.P. and Srijoy, G. (2015) Thyroidectomy under Regional Anaesthesia: An ORL Perspective. Journal of Clinical and Diagnostic Research, 9, MC01-MC04.

[5] Banasiewicz, T., Meissner, W., Pyda, P., Wierzbicki, T., Biczysko, M., Glyda, M., Iwanik, K. and Drews, M. (2011) Local Anaesthesia in Thyroid Surgery-Own Experience and Literature Review. Polski Przeglad Chirurgiczny Journal, 83, 564-570. https://doi.org/10.2478/v10035-011-0041-5

[6] Spanknebel, Chabot, J.A., Di Giorgi, M., Cheung, K., Lee, S., Allendor, F.J. and Logerfo, P. (2005) Thyroidectomy Using Local Anaesthesia: A Report of 1,025 Cases over 16 Years. Journal of the American College of Surgeons, 201, 375-385. https://doi.org/10.1016/j.jamcollsurg.2005.04.034

[7] Kamran, M., Amjad, M. and Kazami, S. (2016) Thyroidectomy under Local Anesthesia. Journal of surgery Pakistan, 21, 58-61.

http://old.jsp.org.pk/Issues/JSP\%2021\%20(2)\%20April\%20-\%20June\%202016\%20P DF/Muhammad\%20Kamran\%20Ch\%20OA.pdf

https://doi.org/10.21699/jsp.21.2.5

[8] Misauno, M.A., Yilkudi, M.G., Akwaras, A.L., Embu, H.Y., Ojo, E.O., Dakum, N.K., Sule, A.Z. and Ugwu, B.T. (2008) Thyroidectomy under LA: How Safe. Nigeria Journal of Clinical Practice, 2, 37-40.

https://www.njcponline.com/article.asp?issn=1119-3077;year=2008; volume=11;issu $\mathrm{e}=1 ;$ spage $=37$; epage $=40$; aulast $=$ Misauno type $=0$

[9] Eke, B.A., Ojo, B.A., Yongu, W.T., Ahaohi, C., Ugwu, V.I., et al. (2017) Subtotal Thyroidectomy for Giant Goitres under LA: Experience with 15 Nigerians. British Journal of Medicine, 19, 1-5. https://doi.org/10.9734/BJMMR/2017/25568

[10] Rifat, L., Joan, H. and Renato, R. (2015) Total Thyroidectomy for a Giant Goitre under Local Anaesthesia and Ketamine in a Surgical Mission. International Journal of Surgery Case Reports, 8, 52-54. https://doi.org/10.1016/j.ijscr.2015.01.007

[11] Chintale, S.G., Kirdak, V.R., Jatale, S.P. and Shaihk, K. (2017) Our Experience of 200 Cases of Thyroid Surgery under Local Anaesthesia versus General Anaesthesia. International Journal of Otorhinolaryngology and Head and Neck Surgery, 3, 683686. https://doi.org/10.18203/issn.2454-5929.ijohns20173047

[12] Kamran, C., Amjad, M. and Kazami, S. (2016) Thyroidectomy under Local Anesthesia. Journal of Surgery Pakistan, 21, 58-61. https://doi.org/10.21699/jsp.21.2.5

[13] Ahmad, A., Amin, M.I., Hossain, H.S.M. and Chawdhury, M.M.O. (2016) Thyroid surgery under Local Anaesthesia: Study of 30 Cases. Journal of Current and Advance Medical Research, 3, 56-59. http://www.banglajol.info/index.php/JCAMR https://doi.org/10.3329/jcamr.v3i2.36166

[14] Acar, H. (2020) Local Regional Anaesthesia in Toxic Goitre Surgery. Indian Journal of Surgery. https://doi.org/10.1007/s12262-020-02550-y 
[15] Belitova, M., Pandev, R. and Karadimov, D. (2012) General or Local Anaesthesia in One-Day Thyroid Surgery-Does It Matter? Balkan Medical Journal, 29, 124-128. https://doi.org/10.5152/balkanmedj.2012.006

[16] Aliyu, S., Ningi, A.B. and Rabi'u, M.B. (2020) Thyroidectomy under Local Anaesthesia in a Poor Resource Health Facility in Northeastern Nigeria. Journal of Surgical Research, 6, 1-5. https://doi.org/10.17352/2455-2968.000084

[17] Ojuka, K.D., Saidi, H. and Reve, E.C. (2013) The Role of Infiltrative Local Anaesthesia in Thyroidectomy. The Annals of African Surgery, 10, 30-32.

[18] Banasiewicz, T., Meissner, W., Pyda, P., Wierzbicki, T., Biczysko, M., Glyda, M., Iwanik, K. and Drews, M. (2008) Partial Thyroidectomy under Local AnaesthesiaThe Analysis of 49 Subsequent Cases. Langenbeck's Archives of Surgery, 393, 715719. https://doi.org/10.1007/s00423-008-0345-Z 